\title{
Extraction of Hyaluronic Acid from Rabbit Skin with Lanthanum Ghloride
}

\author{
Hiroshi Munakata and Zensaku Yosizawa \\ Department of Biochemistry, Tohoku University School of \\ Medicine, Sendai 980
}

\begin{abstract}
Monakata, H. and Yosizawa, Z. Extraction of Hyaluronic Acid from Rabbit Skin with Lanthanum Chloride. Tohoku J. exp. Med., 1980, 132 (3), 337-340The defatted rabbit skin was extracted with $0.5 \mathrm{M} \mathrm{LaCl}$, and the extract was dialyzed exhaustively against distilled water. The precipitate formed during dialysis was dissolved in $28 \mathrm{mM}$ EDTA (ethylenediamine tetraacetate) ( $\mathrm{pH} 7.0$ ). Fr. A was obtained from the solution by precipitation with ethanol in the presence of sodium acetate. The results of gel filtration on Sepharose 4B, electrophoresis on cellulose acetate membrane before and after digestion with Streptomyces hyaluronidase, and analytical data indicated that Fr. A was hyaluronic acid with high molecular weight. The present observation together with previous findings suggest that the binding status of proteoglycans in the skin differs significantly from that in cartilages. .......... hyaluronic acid; rabbit skin; lanthanum chloride
\end{abstract}

Lanthanum chloride was used by Doganges and Schubert (1964) to separate proteoglycan from chondroitin sulfate. Subsequently, Mason and his co-workers (Mason and Mayes 1973; Mayes et al. 1973; Mason and Roughley 1974) reported a simple method, using $\mathrm{LaCl}_{\mathbf{3}}$, for the isolation of proteoglycan from cartilage. Roughley et al. (1978) reported that extraction of cartilage with $0.5 \mathrm{M} \mathrm{LaCl}_{3}$ followed by precipitation on dilution with 9 volumes of water provided a useful initial step for the isolation and separation of proteoglycan and hyaluronic acid. As this method does not involve $\mathrm{CsCl}$ density gradient centrifugation, it is more economical both in time and cost than alternative high ionic strength extraction procedure. Recently, Futami et al. (1979) used this method for extraction of carbohydrate-containing substances from non-calcified and calcified portions of bovine costal cartilage, and found that the remodeling of proteoglycan and consumption of glycogen occur on calcification in the cartilage.

In an attempt to isolate proteoglycans from rabbit skin, the defatted tissues were extracted with $0.5 \mathrm{M} \mathrm{LaCl}_{3}$, and hyaluronic acid was only obtained from the extract. This paper reports the results of the study.

\section{Materials and Methods}

Materials. Hyaluronic acid was prepared from human umbilical cord according to the method of Danishefsky and Bella (1966). Streptomyces hyaluronidase and lanthanum

Received for publication, November 5, 1979. 
chloride $\left(\mathrm{LaCl}_{3} \cdot 7 \mathrm{H}_{2} \mathrm{O}\right)$ were purchased from Seikagaku Kogyo Co., Tokyo, and Wako Junyaku Co., Osaka, respectively. Other materials were commercial products.

Animals. Healthy adult rabbits were fed ad libitum, and hairs were cut with a hair clipper before sacrifice. After slaughtering each animal, skin was cut off with scissors. The subcutaneous adipose tissues were removed completely from the skin with scissors. The skin was then cut into small pieces, and the pieces were put into dry ice-acetone mixture.

Extraction of complex saccharides. The defatted tissues with acetone were extracted with 10 volumes $\left(\mathrm{W} / \mathrm{V}\right.$ ) of $0.5 \mathrm{M} \mathrm{LaCl}_{3}$ for $24 \mathrm{hr}$ at $4^{\circ} \mathrm{C}$. The extract was then filtered through filter paper (Toyo, No. 2) and the filtrate was centrifuged at $8,000 \mathrm{rpm}$ for $30 \mathrm{~min}$. The supernatant was diluted with 9 volumes of water. Since no precipitate was formed on dilution, the solution was dialyzed against several changes of 50 volumes of distilled water for 3 days. The precipitate formed during dialysis was collected by centrifugation, and suspended in $28 \mathrm{mM}$ EDTA ( $\mathrm{pH}$ of this solution was adjusted to 7.0 with $1 \mathrm{M} \mathrm{NaOH}$ ), followed by stirring gently for $3 \mathrm{hr}$ at $4^{\circ} \mathrm{C}$. A small amount of the insoluble matter was removed by centrifugation. Solid sodium acetate was added to the supernatant to give a final concentration of $5 \%(\mathrm{~W} / \mathrm{V})$, and the solution was left to stand for $2 \mathrm{hr}$ at $4{ }^{\circ} \mathrm{C}$. Two volumes of ethanol were added to the solution, and the mixture was left to stand overnight at $4^{\circ} \mathrm{C}$. The precipitate thus formed was collected by centrifugation, and then dissolved in distilled water. The solution was dialyzed against distilled water, and the non-dialyzable fraction was lyophilized, yielding Fr. A.

Electrophoresis. Electrophoresis was carried out on cellulose acetate membrane (Separax) $(6 \times 3.5 \sim 5 \mathrm{~cm})$, in formic acid-pyridine buffer $(\mathrm{pH} 3.0)$ at $2 \mathrm{~mA} / \mathrm{cm}$ for $15 \mathrm{~min}$, and in $0.06 \mathrm{M}$ veronal buffer $(\mathrm{pH} 8.6)$ at $2 \mathrm{~mA} / \mathrm{cm}$ as deseribed previously (Munakata and Yosizawa 1978). The substances were located by staining with alcian blue $(0.05 \%$ in $0.1 \%$ acetic acid). The periodic acid-Schiff (PAS) reaction and the Amidoblack $10 \mathrm{~B}$ staining were also used for checking the PAS-positive substance and protein, respectively.

Enzymic digestion. Digestion with Streptomyces hyaluronidase was performed by the method of Ohya and Kaneko (1970).

Determination of constituents. Hexosamine was determined by the method of Boas (1953). Hexuronic acid was determined by the carbazole method of Dische (1947) or Bitter and Muir (1962), and by the orcinol method of Khym and Doherty (1952).

Gel filtration on Sepharose $4 B$. A solution $(2 \mathrm{mg}$ in $3 \mathrm{ml}$ ) of Fr. A in $50 \mathrm{mM}$ potassium phosphate buffer ( $\mathrm{pH} 7.0$ ) was subjected to gel filtration through a column $(2.5 \times 90 \mathrm{~cm})$ of Sepharose $4 B$ pre-equilibrated with the same buffer. Elution was carried out with the same buffer at a flow rate of $10 \mathrm{ml} / \mathrm{hr}$. Fractions of $9.5 \mathrm{ml}$ were collected, and the hexuronic acid content in each fraction was determined.

\section{Results}

\section{Extraction of complex saccharides}

The defatted tissues of rabbit skin were extracted with 10 volumes of $0.5 \mathrm{M}$ $\mathrm{LaCl}_{3}$, and the extract was diluted with 9 volumes of water, followed by dialysis against distilled water. The precipitate formed during dialysis contained hexuronic acid, but no hexuronic acid was detected in the supernatant. Fr. A was then obtained from the precipitate by the procedures as described in "MATERIALS and Merthods". The yield of Fr. A was $18 \mathrm{mg}$ from $120 \mathrm{~g}$ of the wet tissues.

\section{Characterization of Fr. A}

A portion (2 mg) of Fr. A was subjected to gel filtration on Sepharose 4B as described in "Materials and Methods". Fr. A was eluted at the void volume (Fig. 1), suggesting high molecular weight of the substance. 
Fr. A was examined by electrophoresis on cellulose acetate membrane (Separax) (Fig. 2). Fr. A gave single band at $\mathrm{pH} 3.0$ and $\mathrm{pH} 8.6$, stainable with alcian blue. The mobility of the band was identical with that of authentic hyaluronic acid. This band disappeared after digestion with Streptomyces hyaluronidase. No band was detected by the staining with Amidoblack 10B for protein or by the PAS reaction for glycoprotein and glycogen.

Fr. A contained hexosamine $(41.0 \%$ as glucosamine) and hexuronic acid (45.2

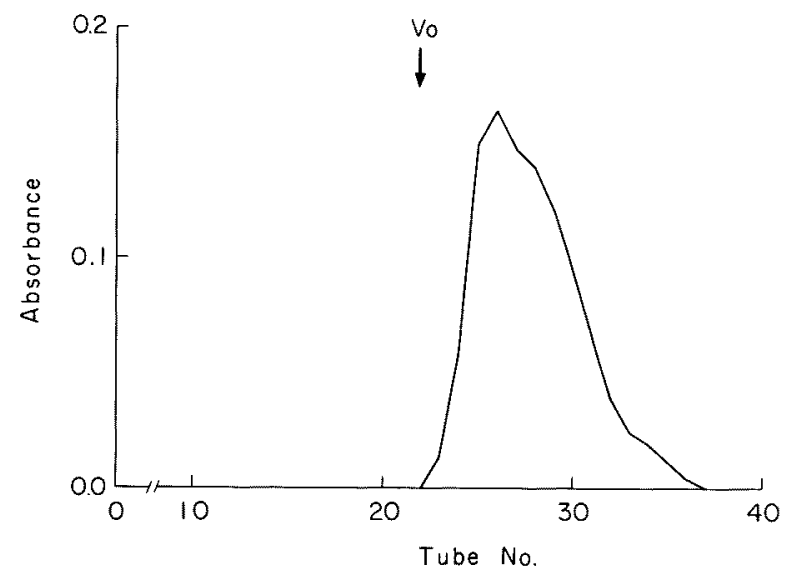

Fig. 1. Gel filtration on Sepharose 4B of Fr. A. Absorbance at $530 \mathrm{~nm}$ in the carbazole reaction for hexuronic acid was plotted. Vo, void volume.

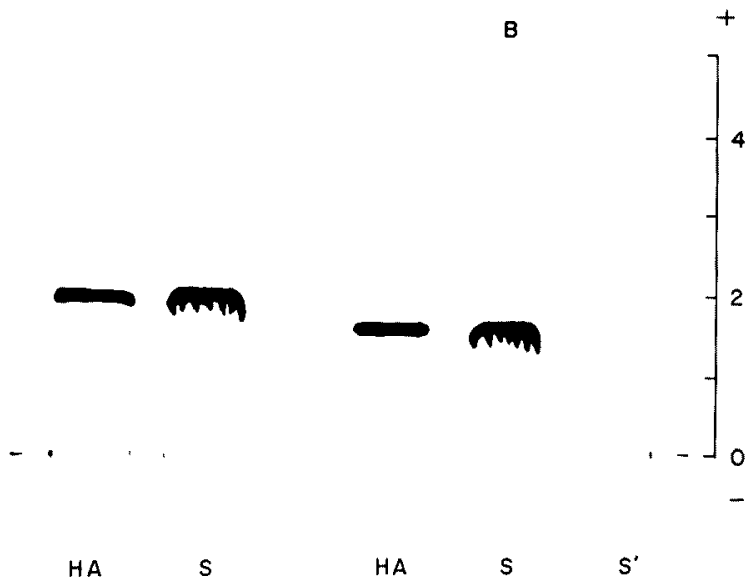

Fig. 2. Electrophoretogram on cellulose acetate membrane of Fr. A, before and after digestion with Streptomyces hyaluronidase, in formic acid-pyridine buffer ( $\mathrm{pH} 3.0$ ) at $2 \mathrm{~mA} / \mathrm{cm}$ for $15 \mathrm{~min}$ (A) and in $0.06 \mathrm{M}$ veronal buffer $(\mathrm{pH} 8.6$ ) at $2 \mathrm{~mA} / \mathrm{cm}$ for $15 \mathrm{~min}$ (B). The substances were located by staining with alcian blue. HA, authentic hyaluronic acid; S, Fr. A; S', the digestion product of Fr. A with Streptomyces hyaluronidase. 
$\%$ as glucuronic acid). C/O ratio (the ratio of carbazole value to orcinol value of hexuronic acid) was 1.3 .

These observations indicate that Fr. A is hyaluronic acid.

\section{Discussion}

Rabbit skin was extracted with $0.5 \mathrm{M} \mathrm{LaCl}_{3}$, and the extract was diluted with 9 volumes of water. Since no precipitate was formed on dilution, the diluted solution was dialyzed exhaustively against distilled water. The precipitate formed during dialysis contained hyaluronic acid. Only hyaluronic acid was isolated from the $\mathrm{LaCl}_{3}$-extract, suggesting that other proteoglycans might be tightly bound to the matrix in the rabbit skin. Since the yield of hyaluronic acid was low, the remaining hyaluronic acid might also be bound tightly to the matrix.

Contrary to the present finding, proteoglycans and hyaluronic acid were easily extracted from cartilages with $0.5 \mathrm{M} \mathrm{LaCl}_{3}$ (Mason and Mayes, 1973; Mayes et al. 1973; Mason and Roughley 1974; Roughley et al. 1978; Futami et al. 1979). These observations suggest that the binding status of proteoglycans in the skin differs significantly from that in cartilages.

\section{References}

1) Bitter, T. \& Muir, H.M. (1962) A modified uronic acid carbazole reaction. Analyt. Biochem., 4, 330-334.

2) Boas, N.F. (1953) Method for the determination of hexosamines in tissues. J. biol. Chem., 204, 553-563.

3) Danishefsky, I. \& Bella, A., Jr. (1966) The sulfated mucopolysaccharides from human umbilical cord. J. biol. Chem., 241, 143-146.

4) Dische, Z. (1947) A new specific color reaction of hexuronic acid. J. biol. Chem., 167, 189-198.

5) Doganges, P.T. \& Schubert, M. (1964) The use of lanthanum to study the degradation of a proteinpolysaccharide from cartilage. J. biol. Chem., 239, 1498-1503.

6) Futami, T., Ototani, N., Nagatsuka, Y. \& Yosizawa, Z. (1979) Comparison of carbohydrate-containing substances from non-calcified and calcified portions of bovine costal cartilage. J. Biochem., 85, 1067-1073.

7) Khym, J.X. \& Doherty, D.G. (1952) The analysis and separation of glucuronic and galacturonic acids by ion exchange. $J$. Amer. chem. Soc, 74, 3199-3200.

8) Mason, R.M. \& Mayes, R.W. (1973) Extraction of cartilage protein-polysaccharides with inorganic salt solutions. Biochem $J ., 131,535-540$.

9) Mason, R.M. \& Roughley, P.J. (1974) Aggregation of cartilage proteoglycans extracted with lanthanum chloride. Biochem. soc. Trans., 2, 894-896.

10) Mayes, R.W., Mason, R.M. \& Griffin, D.C. (1973) The composition of cartilage proteoglycans. An investigation using high- and low-ionic-strength extraction procedures. Biochem. J., 131, 541-553.

11) Munakata, H. \& Yosizawa, Z. (1978) Isolation and characterization of a sulfated glycoprotein from rabbit small intestine. J. Biochem., 84, 1587-1592.

12) Ohya, T. \& Kaneko, Y. (1970) Novel hyaluronidase from Streptomyces. Biochim. biophys. Acta, 198, 607-609.

13) Roughley, P.J., Hatt, M. \& Mason, R.M. (1978) Physicochemical properties of cartilage proteoglycans extracted by lanthanum chloride. Biochim. biophys. Acta, $539,445-458$. 